\title{
Decolonization of the Skin of the Patient and Surgeon
}

\author{
LENA M. NAPOLITANO
}

\begin{abstract}
Objective: To review the evidence regarding antisepsis and decolonization of the skin of the patient and surgeon for the prevention of surgical site infection (SSI).

Data Sources: General bibliographic and specialist computer databases, along with manual searching of reference lists of primary and review articles, were used to search for relevant peer-reviewed citations.

Results: Antisepsis of the surgical site and of the hands of the surgeon is a mainstay in the prevention of SSI. Waterless and scrubless alcohol-based products are an alternative to traditional antiseptic scrubs. Chlorhexidine-based products for skin preparation at the surgical site have proved superior to other preparation products for bacterial decolonization. The efficacy of routine preoperative decolonization strategies, including the use of nasal mupirocin ointment and antiseptic body washes, has not been established definitively by randomized clinical trials.

Conclusions: Antisepsis of the skin of patient and surgeon are important in the prevention of SSI. Preoperative decolonization strategies for prevention of SSI, particularly those caused by antibiotic-resistant organisms, remain controversial.
\end{abstract}

$\mathbf{I}^{\mathrm{N}}$ NFECTIONS OF THE SURGICAL SITE may compromise the outcome of the operation and, under certain circumstances, endanger the life of the patient. Antisepsis of the surgical site and of the surgeon's hands is a mainstay of the prevention of surgical site infection (SSI) through conditions of asepsis, which is defined as performance of a process or procedure under conditions in which bacterial contamination has been minimized.

The most common mode of transmission of pathogens is via hands, and substantial evidence exists that hand hygiene reduces the incidence of infections [1]. The studies of Semmelweis and Holmes are the foundation of the identification of handwashing as one of the most important measures to be taken by healthcare practitioners to reduce cross-contamina- tion. In 1847, Dr. Ignaz Semmelweis, a Viennese physician, discovered that fatal infections were spread among patients by physicians who failed to wash their hands between examinations [2]. Semmelweis instituted a disinfecting procedure whereby physicians were required to wash in a chloride of lime solution after autopsies and with soap and water between patient visits. Doctors also had to change into clean coats before examining patients. As a result, hospital mortality rates from infectious diseases declined.

Handwashing by clinical staff is the single most important measure for preventing transmission of nosocomial infection. Today, handwashing should be a simple, standard antiseptic technique. However, studies conducted at hospitals worldwide have documented that

Division of Acute Care Surgery, University of Michigan School of Medicine, Ann Arbor, Michigan. 
compliance with handwashing is poor in the healthcare setting.

Since the late 1800s, when Lister promoted the application of carbolic acid to the hands of surgeons before procedures, preoperative cleansing of the hands and forearms with an antiseptic agent has been an accepted practice $[3,4]$. In the next section, we review the evidence regarding antisepsis and decolonization of both patient and surgeon in efforts to prevent SSI.

\section{GUIDELINES FOR SURGEON HAND ANTISEPSIS}

The Centers for Disease Control and Prevention (CDC) Guideline for Handwashing and Environmental Control was first published in 1985 and provided basic recommendations for hand hygiene [5]. The subsequent comprehensive CDC Guideline for Hand Hygiene in Health-Care Settings, published in 2002, provides evidence-based recommendations of the Healthcare Infection Control Practices Advisory Committee (HICPAC) and the HICPAC/Society of Healthcare Epidemiologists of America (SHEA)/Association of Professionals in Infection Control (APIC)/Infectious Diseases Society of America (IDSA) Hand Hygiene Task Force [1]. A section on "Surgical Hand Antisepsis" was included, and the final recommendations are listed in Table 1.

The Guideline for the Prevention of Surgical Site Infection [6], published in 1999, is an evidence-based comprehensive summary issued by the CDC and HICPAC. A summary and re- view of these evidence-based guidelines was also published, and summary recommendations for patient and surgeon antisepsis were provided (Table 2) [7]. In 2002, the CDC MMWR (Morbidity and Mortality Weekly Report) Guideline for Hand Hygiene in the Healthcare Setting 10-25-2002 recommended that "Surgical hand antisepsis using either an antimicrobial soap (2-5 min scrub) or an alcohol-based handrub with persistent activity is recommended before donning sterile gloves when performing surgical procedures (Category 1B recommendation)." The World Health Organization (WHO) Guidelines on Hand Hygiene in Health Care (Advanced Draft) [8] was published recently as part of the World Alliance for Patient Safety's Global Patient Safety Challenge 2005-2006 entitled "Clean Care is Safer Care" and "Clean Hands are Safer Hands." This worldwide guideline reiterates the CDC Hand Hygiene Guideline with regard to surgical hand antisepsis.

\section{ISSUES IN SURGICAL HAND HYGIENE AND ANTISEPSIS}

Perioperative surgical hand hygiene is a complex issue. The usual surgical antisepsis involves scrubbing the skin with antiseptic solutions. This procedure can damage the skin, with a paradoxical subsequent higher risk of infection for the patient. There now are several efficient and quick-acting antiseptic alcohol solutions that require no scrubbing. Because of their efficacy, persistent effect, and skin protection, many experts have advised that classi-

Table 1. Surgical Hand Antisepsis: Recommendations of the U.S. Centers for Disease Control and Prevention

Remove rings, watches, and bracelets before beginning the surgical hand scrub (Category II).

Remove debris from underneath fingernails using a nail cleaner under running water (Category II).

Surgical hand antisepsis using either an antimicrobial soap or an alcohol-based hand rub with persistent activity is recommended before donning sterile gloves when performing surgical procedures (Category IB).

When performing surgical hand antisepsis using an antimicrobial soap, scrub hands and forearms for the length of time recommended by the manufacturer, usually 2-6 min. Long scrub times (e.g., 10 min) are not necessary (Category IB).

When using an alcohol-based surgical hand-scrub product with persistent activity, follow the manufacturer's instructions. Before applying the alcohol solution, wash hands and forearms with a non-antimicrobial soap and dry them completely. After application of the alcohol-based product as recommended, allow hands and forearms to dry thoroughly before donning sterile gloves (Category IB)

From reference 4 . 
Table 2. Summary of Evidence-based Guidelines for Prevention of SSI from Centers for Disease Control and Prevention

Preparation of the patient

Category 1A Identify and treat all infections remote from the surgical site before elective operations; postpone operation until infection has resolved

Do not remove hair unless it is at or near the incision site and will interfere with surgery. If hair is removed, this should be done immediately beforehand, preferably with electric clippers.

Category 1B Control the blood glucose concentration in all diabetic patients and avoid hyperglycemia perioperatively

Encourage abstinence from tobacco for a minimum of 30 days before surgery

Do not withhold indicated blood donations as a means to prevent SSI

Patients should shower or bathe with an antiseptic solution at least the night before surgery

Wash and clean the incision site to remove gross skin contamination prior to the antiseptic skin preparation with an appropriate agent

Category $2 \quad$ Prepare area by application of the antiseptic agent in concentric circles. The prepared area should be large enough to accommodate any necessary drains or stomas.

Keep the preoperative hospital stay as short as possible consistent with adequate preparation for surgery

Hand/forearm antisepsis

Category 1B Keep nails short; do not wear artificial nails

Scrub the hands and forearms up to the elbows for at least 2 to 5 min with an appropriate antiseptic

After the scrub, keep hands and arms up and away from the body so that water runs from the fingertips to the elbows. Dry with a sterile towel before donning sterile gown and gloves

Category $2 \quad$ Clean under each fingernail before the first scrub of the day

Unresolved: $\quad$ There is no recommendation regarding the wearing of nail polish

Infected/colonized surgical personnel

Category 1B Educate and encourage personnel with signs and symptoms of a transmissible infectious disease to report it promptly to supervisors and occupational health officials

Develop and maintain policies regarding patient-care responsibilities when personnel have potentially transmissible infections

Obtain cultures from and exclude from duty personnel with draining skin lesions until infection is ruled out or the lesion has responded to anti-infective therapy

Do not routinely exclude from patient care those personnel colonized with organisms such as Staphylococcus aureus or group A streptococci unless an epidemiologic link with dissemination has been established

Antimicrobial prophylaxis

Category 1A Administer antibiotic prophylaxis only when indicated and only when efficacious against the pathogens most commonly causing SSI for the particular operation

Administer initial dose intravenously, timed such that a bactericidal concentration of the drug is present in the serum and tissues when the incision is made.

Maintain therapeutic concentrations of the agent in the serum and tissues for the duration of the operation. Therapeutic levels should be maintained at most only until a few hours after the incision is closed

Before elective colon operations, prepare the colon mechanically with enemas or cathartic agents. Administer nonabsorbable oral antimicrobial agents in multiple doses on the day before surgery

For high-risk cesarian section, administer the prophylactic antibiotic agent immediately after the umbilical cord is clamped

Category 1B Do not use vancomycin routinely for surgical prophylaxis

Surgical attire and drapes

Category $1 \mathrm{~B} \quad$ Wear surgical mask to cover the mouth and nose fully for the duration of the operation or while sterile instruments are exposed*

Wear a cap or hood so as to cover all hair on head and face fully*

Wear sterile gloves after a sterile gown is donned (all scrubbed surgical team members)*

Do not wear shoe covers for the prevention of SSI*

The surgical gowns and drapes used should be effective barriers when wet

Change scrub suits that are visibly soiled or contaminated by blood or other potentially infectious materials 
Table 2. Summary of Evidence-based Guidelines for Prevention of SSI from Centers for Disease Control and Prevention (Cont'd)

\begin{tabular}{|c|c|}
\hline Unresolved & $\begin{array}{l}\text { No recommendations are made about restricting scrub suits to the operating suite or } \\
\text { covering them when out of the suite }\end{array}$ \\
\hline \multicolumn{2}{|c|}{ Asepsis and surgical technique } \\
\hline Category $1 \mathrm{~A}$ & $\begin{array}{l}\text { Adhere to principles of asepsis when placing intravascular devices or when dispensing or } \\
\text { administering intravenous drugs }\end{array}$ \\
\hline \multirow[t]{3}{*}{ Category $1 \mathrm{~B}$} & $\begin{array}{l}\text { Handle tissue gently, maintain hemostasis, minimize devitalized or charred tissue and } \\
\text { foreign bodies, and eradicate dead space at the surgical site }\end{array}$ \\
\hline & $\begin{array}{l}\text { Use delayed primary skin closure or allow incisions to heal by secondary intention if the } \\
\text { surgical site is contaminated or dirty }\end{array}$ \\
\hline & $\begin{array}{l}\text { Use closed suction drains when drainage is necessary, placing the drain through a separate } \\
\text { incision distant from the operative incision. Remove drains as soon as possible }\end{array}$ \\
\hline Category 2 & Assemble sterile equipment and solutions immediately prior to use \\
\hline \multicolumn{2}{|c|}{ Postoperative incision care } \\
\hline \multirow[t]{3}{*}{ Category 2} & $\begin{array}{l}\text { Keep a sterile dressing for } 24 \text { to } 48 \mathrm{~h} \text { postoperatively on an incision closed primarily. } \\
\text { No recommendation is made regarding keeping a dressing on the wound beyond } 48 \mathrm{~h} \text { or } \\
\text { for bathing and showering after the bandage is removed }\end{array}$ \\
\hline & $\begin{array}{l}\text { Wash hands before and after changing dressings and any contact with the surgical site. Use } \\
\text { sterile technique to change dressings }\end{array}$ \\
\hline & $\begin{array}{l}\text { Educate the patient about SSI, relevant symptoms and signs, and the need to report them if } \\
\text { noted }\end{array}$ \\
\hline Unresolved & $\begin{array}{l}\text { No recommendation is made with respect to keeping an incision covered for more than } \\
48 \mathrm{~h}\end{array}$ \\
\hline
\end{tabular}

*Regulated by the U.S. Occupational Health and Safety Administration.

Recommendations for intraoperative ventilation, cleaning and disinfection of environmental surfaces, sterilization of surgical instruments, epidemiologic investigations in the operating room, and surveillance may be found in the source document.

SSI = surgical site infection.

Modified from reference 1 .

cal scrubbing with antiseptic solutions be replaced with gentle washing with a waterless alcohol solution [9].

The introduction of waterless, scrubless alcohol-based hand antiseptics into the operating room, where traditional scrubbing has been the standard, requires education for proper application and initiation of programs to monitor methodology and compliance. The integration of these rinseless products has been challenging. Contributing to the confusion is the U.S. Food and Drug Administration (FDA) statement that products considered to be surgical scrubs must show characteristics that include immediate microbial killing, broad-spectrum activity, and persistence of the effect for as long as six hours.

One of the largest surgical antisepsis studies compared hand rubbing with aqueous alcohol (75\% aqueous alcoholic solution containing propanol-1, propanol-2, and mecetronium etilsulfate) with traditional scrubbing with an antiseptic preparation containing $4 \%$ povidone- iodine or $4 \%$ chlorhexidine gluconate. A total of 4,387 consecutive patients who underwent clean and clean-contaminated surgery were studied in a randomized equivalence trial [10]. The 30-day SSI rates were 55 of 2,252 (2.44\%) with the hand-rubbing protocol and 53 of 2,135 $(2.48 \%)$ with the hand-scrubbing protocol, for a difference of $0.04 \%$ (95\% confidence interval, $-0.88 \%, 0.96 \%$ ) (Table 3 ). Compliance with the recommended duration of hand antisepsis was better in the hand-rubbing than the handscrubbing protocol ( $44 \%$ vs. $28 \%$, respectively; $\mathrm{p}=0.008)$, as was tolerance, with less skin dryness and irritation after aqueous alcohol use. Hand rubbing with aqueous alcoholic solution, preceded by a 1-min nonantiseptic hand wash before each surgeon's first procedure of the day and before any procedure if the hands were soiled, was as effective as traditional hand scrubbing in preventing SSIs. The hand-rubbing protocol was tolerated better by the surgical teams and improved compliance with hygiene guidelines, leading to the conclusion that 
Table 3. Surgical Site Infecton (SSI) Rates and Differences between Hand Scrubbing and Hand Rubbing

\begin{tabular}{|c|c|c|c|c|}
\hline \multirow{2}{*}{$\begin{array}{l}\text { Altemeier class } \\
\text { of } \\
\text { contamination }\end{array}$} & \multicolumn{2}{|c|}{ No. SSI/no. operations (\%) } & \multirow{2}{*}{$\begin{array}{l}\text { Percent } \\
\text { difference in SSI } \\
\text { rate, scrubbing vs. } \\
\text { rubbing }(95 \% \mathrm{CI})\end{array}$} & \multirow{2}{*}{$\begin{array}{l}\chi^{2} \text { test of } \\
\text { equivalence } \\
\text { (p value) }\end{array}$} \\
\hline & Hand scrubbing & Hand rubbing & & \\
\hline Clean & 29/1,485 (1.95) & $32 / 1,520(2.11)$ & $-0.15(-1.16,0.85)$ & $16.0(<0.001)$ \\
\hline Clean-contaminated & $24 / 650 \quad(3.69)$ & $23 / 732 \quad(3.14)$ & $0.55(-1.36,2.46)$ & $1.9(0.09)$ \\
\hline All & $53 / 2,135(2.48)$ & $55 / 2,252(2.44)$ & $0.04(-0.88,0.96)$ & $19.5(<0.001)$ \\
\hline
\end{tabular}

$\mathrm{CI}=$ confidence interval.

From reference 10.

hand rubbing with a liquid aqueous alcoholic solution can be used safely for preoperative hand hygiene.

In another study [11], a comparison of five protocols for surgical handwashing confirmed that the alcohol-based antiseptics were associated with significantly lower numbers of colony-forming units in two of the three postscrub samples $(p=0.003, p=0.035)$. The five study protocols were: (1) An initial scrub of 5 min and consecutive scrubs of 3.5 min with $4 \%$ chlorhexidine gluconate; (2) an initial scrub of $3 \mathrm{~min}$ and consecutive scrubs of $2.5 \mathrm{~min}$ with $4 \%$ chlorhexidine gluconate; (3) an initial scrub of $3 \mathrm{~min}$ and consecutive scrubs of $2.5 \mathrm{~min}$ with $5 \%$ povidone-iodine and $1 \%$ triclosan; (4) an initial scrub of 2 min with $4 \%$ chlorhexidine gluconate followed by a $30 \mathrm{sec}$ application of $70 \%$ isopropyl alcohol and $0.5 \%$ chlorhexidine gluconate, and a $30 \mathrm{sec}$ application of $70 \%$ isopropyl alcohol and $0.5 \%$ chlorhexidine gluconate for consecutive scrubs; (5) an initial scrub of 2 min with $4 \%$ chlorhexidine gluconate followed by a $30 \mathrm{sec}$ application of $70 \%$ ethanol and $0.5 \%$ chlorhexidine gluconate, and a $30 \mathrm{sec}$ application of $70 \%$ ethanol and $0.5 \%$ chlorhexidine gluconate for consecutive scrubs. A scrub protocol using alcohol-based antiseptics was as effective as and no more damaging to skin than more time-consuming conventional methods using detergent-based antiseptics.

Similarly, Kac et al. [12] found that hand rubbing with an alcohol-based solution produced a significantly greater reduction in microbiological load than handwashing with unmedicated soap $(p<0.0001$ for palms and $p=$ 0.0003 for fingertips). After hand rubbing, no transient pathogens were recovered, whereas pathogens were recovered after handwashing in two cases. This study also confirmed that rubbing was more efficacious than washing for the decontamination of healthcare workers' hands after contact with patients and patient environments [12]. Handrubbing with an alcohol-based solution also is significantly more efficient in reducing hand contamination than washing with an antiseptic soap [13,14]. Furthermore, it has been recognized that an alcohol-based hand antiseptic used in conjunction with a scrub agent (i.e., after a brief surgical scrub) enhances the effectiveness of decontamination [15].

Additional studies have documented that hand antisepsis with an alcoholic gel regimen is well tolerated and does not cause skin irritation and dryness. In contrast, skin irritation and dryness increased significantly when washing with the unmedicated soap product. Newer alcoholic hand gels that are less irritating than soap may be more acceptable to staff and lead to better hand-hygiene practices $[16,17]$.

Chlorhexidine gluconate and alcohol gel as disinfectants were compared in a randomized trial involving orthopedic surgeons [18]. The hand-washing protocol dictated that all surgeons wash for $5 \mathrm{~min}$ with chlorhexidine before their first case. Thereafter, the surgeon was randomized to wash for $3 \mathrm{~min}$ with either alcohol gel or chlorhexidine. At the end of each procedure, the gloves were removed, and an impression of the surgeon's fingertips was made on an agar plate. The numbers of bacterial colonies present after $24 \mathrm{~h}$ and $48 \mathrm{~h}$ of incubation were recorded for each agar plate by a microbiologist unaware of the washing protocol. Overall, 41 procedures and 82 episodes of hand washing were studied. Four hands $(8 \%)$ were contaminated in the chlorhexidine group compared with 19 (34\%) in the alcohol 
group ( $\mathrm{p}=0.002$; Fisher exact test). In addition, the average colony count was substantially higher in the alcohol group (20 colony forming units [CFU]) than in the chlorhexidine group (5 CFU). However, this is the only study to iden- tify a higher risk of bacterial contamination of surgeons' hands washed with alcohol.

A comparison of the agents currently available for surgical hand antisepsis is presented in Table 4. A working knowledge of the charac-

Table 4. Characteristics, Efficacy, and Indications for Various Classes of Topical Skin Antiseptics

\begin{tabular}{|c|c|c|c|}
\hline & Characteristics & Efficacy & Indications \\
\hline Alcohols & $\begin{array}{l}\text { Excellent germicides } \\
\text { Volatile, flammable } \\
\text { Emollients needed to } \\
\text { prevent drying } \\
\text { Must dry to work } \\
\text { No appreciable activity } \\
\text { after evaporation }\end{array}$ & $\begin{array}{l}\text { Excellent bactericides } \\
\text { (gram-neg. and gram- } \\
\text { pos.), including multi- } \\
\text { resistant pathogens } \\
\text { Excellent against } \\
\text { Mycobacterium tuberculosis } \\
\text { Good virucides (certain } \\
\text { enveloped viruses such } \\
\text { as herpes simplex, } \\
\text { influenza, RSV; HBV less } \\
\text { susceptible; HCV } \\
\text { probably killed) } \\
\text { Good fungicides } \\
\text { Most rapid onset of action }\end{array}$ & $\begin{array}{l}\text { Surgical hand scrubs and } \\
\text { rubs; less for preparation } \\
\text { Not recommended when } \\
\text { soil and debris are } \\
\text { present }\end{array}$ \\
\hline $\begin{array}{l}\text { Chlorhexidine } \\
\text { gluconate }(\mathrm{CHG})\end{array}$ & $\begin{array}{l}\text { Broad spectrum } \\
\text { Binds to corneum stratum } \\
\text { Substantial persistent } \\
\text { activity } \\
\text { Effectiveness increases with } \\
\text { use } \\
\text { Generally non-toxic but } \\
\text { may be ototoxic and } \\
\text { cause corneal damage } \\
\text { Not for use past superficial } \\
\text { layers of skin } \\
\text { Less irritating than many } \\
\text { agents; allergic reactions } \\
\text { uncommon }\end{array}$ & $\begin{array}{l}\text { Excellent antiseptic } \\
\text { Immediate activity slower } \\
\text { than with alcohols } \\
\text { Excellent bactericide, } \\
\text { although stronger against } \\
\text { gram-pos. than gram- } \\
\text { neg. } \\
\text { Minimal activity against } M \text {. } \\
\text { tuberculosis } \\
\text { Effective against enveloped } \\
\text { viruses (herpes simplex, } \\
\text { HIV, CMV) } \\
2 \% \text { CHG somewhat less } \\
\text { effective than } 4 \%\end{array}$ & $\begin{array}{l}\text { Used predominantly for } \\
\text { hand scrubs } \\
\text { Used for hand antisepsis in } \\
\text { high-risk areas such as } \\
\text { ED and ICU } \\
\text { Used for skin preparation } \\
\text { Activity reduced by anionic } \\
\text { surfactants in many hand } \\
\text { lotions } \\
\text { Influenza and RSV }\end{array}$ \\
\hline Iodophors & $\begin{array}{l}\text { Molecular iodine in carrier } \\
\text { solution; amount of free } \\
\text { iodine determines extent } \\
\text { of antimicrobial activity } \\
\text { Antimicrobial activity can } \\
\text { be affected by pH, temp., } \\
\text { exposure time, conc. of } \\
\text { free iodine, presence of } \\
\text { organic and inorganic } \\
\text { compounds } \\
\text { Cause less skin irritation } \\
\text { and fewer allergic } \\
\text { reactions than iodine but } \\
\text { more contact dermatitis } \\
\text { than other antiseptics } \\
\text { commonly used for hand } \\
\text { hygiene }\end{array}$ & $\begin{array}{l}\text { Broad spectrum } \\
\text { Bactericidal (gram-pos. and } \\
\text { gram-neg.) } \\
\text { Active against } \\
\text { mycobacteria, viruses, } \\
\text { and fungi } \\
\text { Activity is substantially } \\
\text { reduced in presence of } \\
\text { organic matter } \\
\text { Poor persistence }\end{array}$ & $\begin{array}{l}\text { Surgical hand scrubs and } \\
\text { skin preparation }\end{array}$ \\
\hline $\begin{array}{l}\text { Parachlorometaxylenol } \\
\text { (PCMX) }\end{array}$ & $\begin{array}{l}\text { Non-allergenic } \\
\text { Concentrations differ } \\
\text { Not as rapidly acting as } \\
\text { CHG or iodophors }\end{array}$ & $\begin{array}{l}\text { Bactericidal (good against } \\
\text { gram-pos.; fair against } \\
\text { gram-neg) } \\
\text { Fair activity against } M \text {. } \\
\text { tuberculosis, some fungi, } \\
\text { certain viruses } \\
\text { Less persistent than CHG } \\
\text { Minimally affected by } \\
\text { organic matter }\end{array}$ & $\begin{array}{l}\text { Surgical scrubs } \\
\text { Handwashing } \\
\text { Neutralized by anionic } \\
\text { surfactants }\end{array}$ \\
\hline
\end{tabular}


Table 4. Characteristics, Efficacy, and Indications for Various Classes of Topical Skin Antiseptics (Cont'd)

\begin{tabular}{|c|c|c|c|}
\hline & Characteristics & Efficacy & Indications \\
\hline Triclosan & $\begin{array}{l}\text { Ideal concentration not } \\
\text { known; } 1 \%-2 \% \\
\text { Activity affected by } \mathrm{pH}, \\
\text { surfactants, emollients, } \\
\text { ionic nature of } \\
\text { formulation } \\
\text { Formulations of }<2 \% \text { well } \\
\text { tolerated and seldom } \\
\text { cause allergic reactions }\end{array}$ & $\begin{array}{l}\text { More effective against } \\
\text { gram-pos. than gram- } \\
\text { neg. } \\
\text { Reasonably active against } \\
\text { M. tuberculosis } \\
\text { Limited activity against } \\
\text { filamentous fungi } \\
\text { Relatively broad-spectrum } \\
\text { activity against viruses } \\
\text { Intermediate speed of } \\
\text { action } \\
\text { Persistent on skin }\end{array}$ & $\begin{array}{l}\text { In 1994, FDA Tentative } \\
\text { Final Monograph stated } \\
\text { "Triclosan less than } 1 \\
\text { percent: insufficient data } \\
\text { exists to classify this } \\
\text { agent as safe and } \\
\text { effective for use as an } \\
\text { antiseptic handwash." } \\
\text { Evaluation continues } \\
\text { Handwash } \\
\text { Consumer products } \\
\text { Suture material }\end{array}$ \\
\hline
\end{tabular}

Abbreviations: $\mathrm{RSV}=$ respiratory syncytial virus; $\mathrm{HBV}=$ hepatitis $\mathrm{B}$ virus; $\mathrm{HCV}=$ hepatitis $\mathrm{C}$ virus; $\mathrm{HIV}=$ human immunodeficiency virus; $\mathrm{CMV}=$ cytomegalovirus; $\mathrm{ED}=$ emergency department; $\mathrm{ICU}$ = intensive care unit; FDA = U.S. Food and Drug Administration.

teristics, efficacy, and appropriate indications of these products is necessary for all practicing surgeons. The microbiologic activities and potential uses of these antiseptics are provided in detail in Table 5.

An alcohol-based product that could be used to decontaminate the hands with or without water (i.e., water optional) while providing immediacy of killing and persistence could reduce the confusion associated with the national handwashing guidelines [19]. Such a product has been developed. Triseptin (Healthpoint, Inc., Fort Worth, TX), which is alcohol-based (61\%) and zinc pyrithione (ZPT)-preserved, is compliant with the FDA and CDC guidelines. The $61 \%$ alcohol-ZPT product easily produced $>3.0 \log _{10}$ reductions in the indicator strain (Serratia marcescens) with the first wash, exceeding the $2.0 \log _{10}$ FDA requirement. This level of performance was maintained through the tenth wash, surpassing the $3.0 \log _{10}$ FDA requirement for the handwash indication. For the assessment of persistence and residual effect in the waterless mode, the water-optional, $61 \%$ alcohol-ZPT product consistently produced $\log _{10}$ reductions of 3.5 or greater at every point over the entire study period. In the water-aided configuration, similar results were obtained, as $\log _{10}$ reductions of 2.5 were observed. The formulation was non-irritating, actually improving hand skin condition. The $61 \%$ alcohol-ZPT product therefore exceeded all FDA criteria for the health care personnel handwash indication and is a substantial advancement in the concept of skin antisepsis in that it is a single product suitable for all handhygiene settings and demonstrates better antimicrobial persistence and residual effects. A previously reported study has documented it to be virucidal for several DNA and RNA viruses [20].

\section{PREOPERATIVE BATHING OR SHOWERING WITH SKIN ANTISEPTICS TO PREVENT SSI}

Preoperative bathing or showering with an antiseptic skin wash product is a well-accepted and commonly recommended procedure for reducing skin bacteria and microflora prior to surgery. The CDC Guideline for the Prevention of Surgical Site Infection now "strongly recommends" (Category IB) that healthcare facilities "require patients to shower or bathe with an antiseptic agent on at least the night before the operative day," as a preoperative antiseptic shower or bath decreased skin microbial colony counts ninefold in the studies they cite. Although the CDC cautions that the showers have not been shown definitively to reduce SSI rates, the practice is sound as it relates to skin microbiology, given the fact that the majority of SSIs are associated with skin flora.

A recent Cochrane systematic review examined six trials of preoperative bathing involving a total of 10,007 participants [21]. The antiseptic used in all trials was $4 \%$ chlorhexidine gluconate. Bathing with chlorhexidine com- 
Table 5. Microbiologic Activities and Potential Uses of Antiseptics

\begin{tabular}{|c|c|c|c|c|c|c|c|c|c|c|c|}
\hline \multirow[b]{3}{*}{ Group } & \multirow{2}{*}{\multicolumn{6}{|c|}{ Spectrum of activity }} & \multicolumn{4}{|c|}{ Potential uses } & \multirow[b]{3}{*}{ Comments } \\
\hline & & & & & & & \multirow{2}{*}{$\begin{array}{l}\text { Speed } \\
\text { of } \\
\text { action }\end{array}$} & \multirow{2}{*}{$\begin{array}{c}\text { Effect of } \\
\text { organic } \\
\text { matter }\end{array}$} & \multirow{2}{*}{$\begin{array}{l}\text { Surgical } \\
\text { scrub }\end{array}$} & \multirow{2}{*}{$\begin{array}{l}\text { Skin } \\
\text { prep. }\end{array}$} & \\
\hline & Gram+ & Gram- & $T B$ & Viruses & Fungi & Endospores & & & & & \\
\hline Alcohols $^{a}$ & Exc & Exc & Exc & Exc & Exc & None & Fast & Mod & Yes & Yes & $\begin{array}{l}\text { Not for use } \\
\text { on mucous } \\
\text { membranes; } \\
\text { not good for } \\
\text { physical } \\
\text { cleaning of } \\
\text { skin; does } \\
\text { not persist }\end{array}$ \\
\hline $\begin{array}{l}\text { Chlorhexidine } \\
\qquad(2-4 \%)\end{array}$ & Exc & Good & Fair & Exc & Fair & None & Int & Slight & Yes & Yes & $\begin{array}{l}\text { Good } \\
\text { persistence; } \\
\text { toxic to eyes } \\
\text { and ears }\end{array}$ \\
\hline Iodine $(3 \%)$ & Exc & Exc & Exc & Exc & Good & Fair & Int & Marked & No & Yes & $\begin{array}{l}\text { Not for use } \\
\text { on mucous } \\
\text { membranes; } \\
\text { can burn } \\
\text { skin, so } \\
\text { remove after } \\
\text { several } \\
\text { minutes }\end{array}$ \\
\hline $\begin{array}{l}\text { Povidone- } \\
\text { iodine } \\
\quad(7.5-10 \%)\end{array}$ & Exc & Exc & Fair & Good & Good & None & Int & Mod & Yes & Yes & $\begin{array}{l}\text { Can be used } \\
\text { on mucous } \\
\text { membranes }\end{array}$ \\
\hline $\begin{array}{l}\text { PCMX } \\
\quad(0.5-4 \%)\end{array}$ & Good & Exc & Fair & Good & Fair & Unknown & Slow & Minimal & No & Yes & $\begin{array}{l}\text { Penetrates } \\
\text { skin; should } \\
\text { not be used } \\
\text { on newborns }\end{array}$ \\
\hline $\begin{array}{l}\text { Triclosan } \\
\quad(0.2-2 \%)\end{array}$ & Exc & Good & Fair & Exc & None & Unknown & Int & Minimal & Yes & No & $\begin{array}{l}\text { Acceptability } \\
\text { on hands } \\
\text { varies }\end{array}$ \\
\hline
\end{tabular}

${ }^{a} 60-90 \%$ ethyl or isopropyl.

Abbreviations: $\mathrm{TB}=$ Mycobacterium tuberculosis $; \mathrm{Exc}=$ excellent; Mod = moderate; Int = intermediate; $\mathrm{PCMX}=$ parachlorometaxylenol.

Adapted from reference 1 and Olmsted RN, ed. Infection control and applied epidemiology: principles and practices. St. Louis, MO: CV Mosby, 1996: table 19-2.

pared with a placebo did not result in a statistically significant reduction in SSIs (relative risk [RR] $0.91 ; 95 \%$ confidence interval [CI] 0.80, 1.04). When only high-quality trials were analyzed, the results were no different (RR 0.95; $95 \%$ CI $0.82,1.0)$. Three trials of 1,443 participants compared bar soap with chlorhexidine; there was no difference in the risk of SSIs (RR 1.02; 95\% CI 0.57, 1.84). Two trials involving 1,092 patients compared bathing with chlorhexidine and no washing; likewise, no difference was found (RR 0.70; 95\% CI 0.19, 2.58). This Cochrane review provides evidence of no benefit for preoperative showering or bathing with chlorhexidine over other wash products. Efforts to reduce the incidence of nosocomial
SSI should focus on interventions where effect has been demonstrated.

\section{ANTISEPSIS OF THE SURGICAL SITE}

Antiseptic preoperative skin site cleansing is used to prepare the operative site before making a surgical incision. The goal is a reduction in postoperative SSI. The usual method is scrubbing the skin with an antiseptic, traditionally povidone-iodine solution. Just as with surgeon hand hygiene, this procedure can damage the skin, possibly increasing the risk of infection. There are several efficient and quickacting antiseptic alcohol solutions that require 
no scrubbing. The traditional preoperative practice is increasingly being replaced by chlorhexidine, which, unlike povidone-iodine, remains active in the presence of blood and serum. One application of chlorhexidine exceeds the FDA criteria for antisepsis in preoperative patient skin preparation. ChloraPrep (2\% chlorhexidine gluconate and $70 \%$ isopropyl alcohol; Medi-Flex, Inc., Leawood, KS) was superior to DuraPrep $(0.7 \%$ iodine and $74 \%$ isopropyl alcohol; 3M Corp., St. Paul, MN) and Techni-Care (3.0\% chloroxylenol; CareTech Laboratories, St. Louis, MO) in eliminating bacteria in a prospective study of 125 consecutive patients undergoing surgery of the foot and ankle [22]. These findings were confirmed in a randomized study [23].

It is crucially important to educate healthcare practitioners in the proper method of application of chlorhexidine solution, which should be scrubbed on for $30 \mathrm{sec}$ in a back-and-forth motion, the friction of which is part of what makes the solution effective. The area does not need be doused or flooded with this agent, as some do with povidone-iodine solution. Scrubbing it on to cover the intended area is sufficient. The prepared area must then be allowed to dry completely, and the solution should not be blotted or wiped away. The preparation contains alcohol; therefore, adequate drying is also important for the prevention of fires caused by electrocautery. One previous difficulty with chlorhexidine skin preparations was the inability to discern that all areas of the skin had been covered, because the solution was colorless. A teal-colored tint has now been added for easier visibility.

If povidone-iodine skin preparation is to be used, there is still the question of whether scruband-paint vs. paint alone is superior. A randomized trial in 240 patients undergoing nonlaparoscopic abdominal operations compared a vigorous 5-minute scrub with povidone-iodine soap followed by absorption with a sterile towel and painting with aqueous povidone-iodine $(n=115)$ with site preparation with povidoneiodine paint only $(n=119)$ [24]. The primary endpoint was the 30-day SSI rate, defined as the presence of clinical signs of infection necessitating therapeutic intervention. The patients in the two groups were well matched with respect to age, co-morbidity, wound classification, mean operative time, placement of drains, prophylactic antibiotic use, and surgical procedure (all $\mathrm{p}>$ 0.09). Surgical site infection occurred in $12(10 \%)$ scrub-and-paint patients and $12(10 \%)$ paintonly patients. According to the predefined parameters, these results were equivalent, suggesting that preoperative preparation of the abdomen with a povidone-iodine soap scrub and painting with aqueous povidone-iodine can be abandoned in favor of painting alone. However, this trial had a small sample size, and validation of the findings is warranted.

\section{SKIN ANTISEPSIS IN CLEAN SURGERY}

It is unclear whether preoperative skin antisepsis actually reduces SSI in clean surgery. A Cochrane review that examined this issue concluded that there is insufficient evidence that cleaning patients' skin with antiseptic before clean surgery reduces SSI [25]. Six eligible randomized controlled trials evaluated antiseptics applied immediately prior to incision in clean surgery. There was significant heterogeneity in the design of studies, however, and the results could not be pooled. In one of these studies, infection rates were significantly lower when skin was prepared using chlorhexidine rather than iodine. There was no evidence of a benefit in four trials that examined the use of iodophor-impregnated drapes.

A recent prospective cohort study compared SSI rates of 905 control patients who underwent skin preparation with normal saline compared with 905 patients for whom either chlorhexidine or povidone-iodine skin preparation was used. In both patient groups, a preoperative shower of the surgical site with soap and water was required. There were no SSIs in any group [26].

\section{STAPHYLOCOCCUS AUREUS NASAL DECOLONIZATION FOR PREVENTION OF SSI}

Staphylococcus aureus remains the most common cause of SSI. The ecologic niche of $S$. aureus is the anterior nares, and nasal colonization by the organism is common. Approximately one-third of humans have skin and mucosal colonization by $S$. aureus, although most 
never become ill as a result. However, carriers are at higher risk for staphylococcal infections after invasive medical or surgical procedures than are non-carriers $[27,28]$.

Decolonization, the use of antibiotics or antiseptics to reduce the magnitude of the reservoir in colonized patients, may be a useful undertaking. Several studies have reported lower rates of SSI among colonized patients who received $2 \%$ mupirocin ointment to the nares than among historical control subjects [29-31], although there is no benefit to the use of mupirocin for non-colonized patients.

A large randomized, double-blind, placebocontrolled trial (the Mupirocin and the Risk of Staphylococcus aureus - MARS - Study) examined whether preoperative nasal decolonization with mupirocin would decrease the rate of $S$. aureus SSI [32]. Overall, 2.3\% of mupirocin recipients and $2.4 \%$ of the placebo recipients had $S$. aureus SSIs among the 3,864 patients in the intent-to-treat analysis, who underwent general, gynecologic, neurologic, or cardiothoracic surgery. Thus, prophylactic intranasal application of mupirocin did not significantly reduce the rate of S. aureus SSIs [32]. Interestingly, it did decrease significantly the rate of all nosocomial $S$. aureus infections among the patients who were carriers $(4.0 \%$ vs. $7.7 \%$; odds ratio [OR] $0.49 ; 95 \%$ CI, 0.25, 0.92; $\mathrm{p}=0.002$ ).

Another randomized study in 395 digestive surgery patients compared intranasal mupirocin $30 \mathrm{mg}$ TID preoperatively for three days with no drug [33]. There were 21 gram-positive SSIs, 10 in the treated group and 11 in the control patients. Thus, intranasal mupirocin treatment had no significant impact on SSI after digestive surgery. However, this study did identify a significant reduction in the incidence of postoperative pneumonia, with none in the mupirocintreated group and five in control patients $(\mathrm{p}=$ 0.028), with MRSA being the causative pathogen in four of the latter five patients.

\section{DECOLONIZATION OF COLONIZED PATIENTS}

A number of surgical patients are colonized with antibiotic-resistant pathogens, particularly methicillin-resistant $S$. aureus (MRSA), in the preoperative period and therefore are at higher risk for SSI with these pathogens. Consensus regarding the optimal preoperative preparation of MRSA-colonized patients, and whether preoperative decolonization should be attempted, has not been achieved. Furthermore, the optimal antimicrobial or antiseptic agents to use for prophylaxis in these colonized patients have not been determined.

A number of studies have documented a reduction in SSI with decolonization, but most were not randomized and controlled [30,34,35]. Topical perioperative prophylaxis for prevention of MRSA SSIs was examined using a controlled before-after approach on patients undergoing insertion of metal orthopedic prostheses or fixation. Patients received perioperative prophylaxis with nasal mupirocin ointment for five days and a shower or bath with $2 \%$ triclosan before surgery. Patients were followed for 12 months postoperatively. After introduction of the decolonization regimen, there was a marked decrease in the incidence of MRSA SSIs, from 23 per 1000 operations in the six months before the regimen to $3.3(p<0.001)$ and $4(\mathrm{p}<0.001)$ in subsequent consecutive six-month periods. Point prevalence nasal carriage of MRSA decreased from 38\% before the decolonization regimen was initiated to $23 \%$ immediately after, and $20 \%, 7 \%, 10 \%$, and $8 \%$ $(\mathrm{p}<0.001)$ at six-monthly intervals post-intervention [36]. Low-level mupirocin resistance was identified in $2.3 \%$ of $S$. aureus isolates from patients before the decolonization regimen was initiated and in $3.9 \%, 6.1 \%, 10 \%$, and $0 \%$ in subsequent six-month periods. Furthermore, no $S$. aureus strains with high-level mupirocin resistance were isolated. The study investigators concluded that this regimen could reduce the incidence of MRSA SSI after orthopedic surgery, probably by reducing endemic nasal MRSA carriage, without selecting for mupirocin resistance. On the other hand, a randomized, placebo-controlled, double-blind trial to evaluate the efficacy of mupirocin for eradicating carriage of MRSA suggested that nasal mupirocin was only marginally effective in the eradication of multi-site MRSA carriage in a setting where MRSA was endemic [37]. The SHEA Guideline for Preventing Nosocomial Transmission of Multidrug-Resistant Strains of Staphylococcus aureus and Enterococcus (May 2003) can be found in Table 6 [38-47]. Similarly, the Guidelines for the Con- 
Table 6. SHEA Guideline for Preventing Nosocomial Transmission of Multidrug-Resistant Strains of Gram-Positive Cocci

Consider MRSA decolonization therapy for both patients and healthcare workers as an adjunctive measure for controlling spread of MRSA in selected populations when appropriate (Category IB)

Any program of decolonization therapy should incorporate routine susceptibility testing, as selection of inactive agents is less likely to achieve eradication (Category II)

Widespread use, prolonged use, or both of decolonization therapy should be avoided, because this has been associated with the evolution and spread of antibiotic-resistant strains, undermining the effectiveness of the control effort (Category IB)

SHEA = Society of Healthcare Epidemiologists of America; MRSA = methicillin-resistant Staphylococcus aureus.

trol and Prevention of MRSA in Healthcare Facilities, published by the Joint Working Party of the British Society of Antimicrobial Chemotherapy, the Hospital Infection Society, and the Infection Control Nurses Association [48] recently published recommendations regarding decolonization (Table 7).

A Cochrane review examined all randomized, controlled trials of MRSA-colonized patients who were decolonized with topical or systemic antimicrobials or given a placebo or no treatment, as well as trials that compared combinations of single topical or systemic agents with no treatment, placebo, or topical or systemic agents [49]. Six trials (384 participants) met the inclusion criteria. No difference in MRSA eradication was detected in four studies: One that compared mupirocin with placebo, two that compared one systemic agent with no treatment (fusidic acid in one and rifampin or minocycline in the other), and one that compared mupirocin with topical fusidic acid and oral trimethoprim-sulfame-thoxazole. One study compared minocycline with rifampin, with rifampin being more effective in the eradication of MRSA from all sites at day 30 (RR 0.16 ; $95 \%$ CI $0.02,1.00)$, but there was no difference at 90 days. Two studies (one testing novobiocin and rifampin, the other cipro-floxacin and rifampin, versus trimethoprim-sulfamethoxazole and rifampin) demonstrated no difference in eradication of MRSA at all sites $(n=94)$. Adverse events occurred in as many as $20 \%$ of participants receiving systemic agents; however, event reporting was sporadic, and denominators were small. All trials detected development of resistance to antimicrobial agents used. The conclusion is that there is insufficient evidence to support use of topical or systemic antimicrobials for eradicating nasal or extra-nasal MRSA, and there is no demonstrated superiority of either topical or systemic therapy, or of combinations of these agents, yet potentially serious adverse events and antimicrobial resistance can result.

Another guideline, the North Carolina Guidelines for Control of Antibiotic-Resistant Organisms [50], states: "Routine decolonization for MRSA is not recommended. The need for decolonization should be based on the patient's medical condition and expected outcome. Topi-

Table 7. Joint British Guidelines for Control and Prevention of MRSA in Healthcare Facilities

\section{Nasal decolonization}

Patients receiving prophylaxis for an operative procedure and in an outbreak situation under the advice of the infection control team should undergo nasal decolonization. This should be undertaken by applying mupirocin $2 \%$ in a paraffin base (ointment) to the inner surface of each nostril (anterior nares) three times daily for five days. The patient should be able to taste mupirocin at the back of the throat after application (Category 1B).

Mupirocin should not be used for prolonged periods or used repeatedly (i.e., for more than two courses for five days), as resistance may be encouraged (Category 1A). The presence of a foreign body such as a nasogastric tube may reduce the efficacy of treatment with nasal mupirocin (Category 2).

Nasal decolonization using topical nasal mupirocin should be used with other forms of intervention such as skin decolonization with $4 \%$ chlorhexidine gluconate aqueous solution (Category 2).

\section{Skin decolonization}

Skin decolonization using $4 \%$ chlorhexidine bodywash/shampoo, $7.5 \%$ povidone-iodine or $2 \%$ triclosan is useful in eradicating or suppressing skin colonization for short times, particularly preoperatively to reduce the risk of SSIs (Category 1A). Patients should bathe daily for five days with the chosen antiseptic detergent. The skin should be moistened and the antiseptic detergent should be applied thoroughly to all areas before rinsing in the bath or shower. Special attention should be paid to known carriage sites such as the axilla, groin and perineal area. The antiseptic should also be used for all other washing procedures and for bed bathing. Hair should be washed with antiseptic detergent (Category 1A).

After satisfactory completion of a course of treatment, clean clothing, bedding and towels should be provided after each bath and hairwash (Category 2).

MRSA $=$ methicillin-resistant Staphylococcus aureus. 
cal or systemic antibiotics, including trimethoprim-sulfamethoxazole, rifampin, ciprofloxacin, erythromycin, doxycycline, bacitracin, and mupirocin have been used with variable results to eradicate colonization by MRSA. Vancomycin is not indicated for decolonization therapy, as it is ineffective for this purpose. There is no clinically proven decolonization regimen for vancomycin-resistant enterococci (VRE)."

\section{REFERENCES}

1. Boyce JM, Pittet D; Healthcare Infection Control Practices Advisory Committee, HICPAC/SHEA/APIC/ IDSA Hand Hygiene Task Force. Guideline for Hand Hygiene in Healthcare Settings. MMWR 2002;51(RR16):1-48.

2. Wyklicky H, Skopec M. Ignaz Philipp Semmelweis, the prophet of bacteriology. Infect Control 1983;4: 367-370.

3. Classic articles in colonic and rectal surgery. On the antiseptic principle in the practice of surgery by Joseph Lister 1867. Dis Colon Rectum 1982;25:173-178.

4. Gröschel DHM, Pruett TL. Surgical antisepsis. In: Block SS, ed. Disinfection, sterilization and preservation. 4th ed. Philadelphia. Lea and Febiger, 1991.

5. Garner JS, Favero MS. CDC Guideline for handwashing and hospital environmental control, 1985. Infect Control 1986;7:231-243.

6. Mangram AJ, Horan TC, Pearson ML, et al. Guideline for prevention of surgical site infection, 1999. Hospital Infection Control Practices Advisory Committee. Infect Control Hosp Epidemiol 1999;20:250-278.

7. Lee JT. A new surgical site infection (SSI) prevention guideline. Surgical Infections 2000;1:127-131.

8. Available at http://www.who.int/patientsafety/ events/05/HH_en.pdf.

9. Herruzo-Cabrera R, Vizcaino-Alcaide MJ, FernandezAcenero MJ. Usefulness of an alcohol solution of Nduopropenide for the surgical antisepsis of the hands compared with handwashing with iodine-povidone and chlorhexidine: Clinical essay. J Surg Res 2000; 94:6-12.

10. Parienti JJ, Thibon P, Heller R, Antisepsie Chirurgicale des Mains Study Group. Hand-rubbing with an aqueous alcoholic solution vs. traditional surgical hand-scrubbing and 30-day surgical site infection rates: A randomized equivalence study. JAMA 2002;288:722-727.

11. Pereira LJ, Lee GM, Wade KJ. An evaluation of five protocols for surgical handwashing in relation to skin condition and microbial counts. J Hosp Infect 1997;36: 49-65.

12. Kac G, Podglajen I, Gueneret M, et al. Microbiological evaluation of two hand hygiene procedures achieved by healthcare workers during routine patient care: A randomized study. J Hosp Infect 2005;60:32-39.
13. Girou E, Loyeau S, Legrand P, et al. Efficacy of handrubbing with alcohol based solution versus standard handwashing with antiseptic soap: Randomised clinical trial. BMJ 2002;325:362-364.

14. Mulberry G, Snyder AT, Heilman J, et al. Evaluation of a waterless, scrubless chlorhexidine gluconate/ ethanol surgical scrub for antimicrobial efficacy. Am J Infect Control 2001;29:377-382.

15. Nishimura C. Comparison of the antimicrobial efficacy of povidone-iodine, povidone-iodine-ethanol and chlorhexidine gluconate-ethanol surgical scrubs. Dermatology 2006;212(Suppl 1):21-25.

16. Boyce JM, Kelliher S, Vallande N. Skin irritation and dryness associated with two hand-hygiene regimens: Soap-and-water hand washing versus hand antisepsis with an alcoholic hand gel. Infect Control Hosp Epidemiol 2000;21:442-448.

17. Larson EL, Aiello AE, Heilman JM, et al. Comparison of different regimens for surgical hand preparation. AORN J 2001;73:412-414, 417-418, 420.

18. Hajipour L, Longstaff L, Cleeve V, et al. Hand washing rituals in trauma theatre: Clean or dirty? Ann $\mathrm{R}$ Coll Surg Engl 2006;88:13-15.

19. Guthery E, Seal LA, Anderson EL. Zinc pyrithione in alcohol-based products for skin antisepsis: Persistence of antimicrobial effects. Am J Infect Control 2005;33:15-22.

20. Seal LA, Rizer RL, Maas-Irslinger R. A unique water optional healthcare personnel handwash provides antimicrobial persistence and residual effects while decreasing the need for additional products. Am J Infect Control 2005;33:207-216.

21. Webster J, Osborne S. Preoperative bathing or showering with skin antiseptics to prevent surgical site infection. Cochrane Database Syst Rev 2006;CD004985.

22. Ostrander RV, Botte MJ, Brage ME. Efficacy of surgical preparation solutions in foot and ankle surgery. I Bone Joint Surg [Am] 2005;87:980-985.

23. Bibbo C, Patel DV, Gehrmann RM, Lin SS. Chlorhexidine provides superior skin decontamination in foot and ankle surgery: A prospective randomized study. Clin Orthop Relat Res 2005;438:204-208.

24. Ellenhorn JD, Smith DD, Schwarz RE, et al. Paint-only is equivalent to scrub-and-paint in preoperative preparation of abdominal surgery sites. I Am Coll Surg 2005;201:737-741.

25. Edwards PS, Lipp A, Holmes A. Preoperative skin antiseptics for preventing surgical wound infections after clean surgery. Cochrane Database Syst Rev 2004; CD003949.

26. Kalantar-Hormozi AJ, Davami B. No need for preoperative antiseptics in elective outpatient plastic surgical operations: A prospective study. Plast Reconstr Surg 2005;116:529-531.

27. Perl TM, Golub JE. New approaches to reduce Staphylococcus aureus nosocomial infection rates: Treating $S$. aureus nasal carriage. Ann Pharmacother 1998;32:S7S16.

28. Wenzel RP, Perl TM. The significance of nasal carriage of Staphylococcus aureus and the incidence of 
postoperative wound infection. I Hosp Infect 1995; 31:13-24.

29. Kluytmans JAJW, Mouton JW, VandenBergh MFQ, et al. Reduction of surgical-site infections in cardiothoracic surgery by elimination of nasal carriage of Staphylococcus aureus. Infect Control Hosp Epidemiol 1996;17:780-785.

30. Cimochowski GE, Harostock MD, Brown R, et al. Intranasal mupirocin reduces sternal wound infection after open heart surgery in diabetics and nondiabetics. Ann Thorac Surg 2001;71:1572-1579.

31. Gernaat-van der Sluis AJ, Hoogenboom-Verdegaal AM, Edixhoven PJ, Spies-van Rooijen NH. Prophylactic mupirocin could reduce orthopedic wound infections: 1,044 patients treated with mupirocin compared with 1,260 historical controls. Acta Orthop Scand 1998;69:412-414.

32. Perl TM, Cullen JJ, Wenzel RP, et al.; the Mupirocin and the Risk of Staphylococcus aureus Study Team. Intranasal mupirocin to prevent postoperative Staphylococcus aureus infections. N Engl J Med 2002;346:1871-1877.

33. Suzuki Y, Kamigaki T, Fujino Y, et al. Randomized clinical trial of preoperative intranasal mupirocin to reduce surgical site infection after digestive surgery. Br J Surg 2003;90:1072-1075.

34. Kluytmans JA, Mouton JW, Banden Bergh MF, et al. Reduction of surgical site infections in cardiothoracic surgery by elimination of nasal carriage of Staphylococcus aureus. Infect Control Hosp Epidemiol 1996;17: 780-785.

35. Yano M, Kodi $Y$, Inoue $M$, et al. Preoperative intranasal mupirocin ointment significantly reduces postoperative infection with Staphylococcus aureus in patients undergoing upper gastrointestinal surgery. Surg Today 2000;30:16-21.

36. Wilcox MH, Hall J, Pike $\mathrm{H}$, et al. Use of perioperative mupirocin to prevent methicillin-resistant Staphylococcus aureus (MRSA) orthopaedic surgical site infections. J Hospital Infection 2003;54:196-201.

37. Harbarth S, Dharan S, Liassine N, et al. Randomized, placebo-controlled, double-blind trial to evaluate the efficacy of mupirocin for eradicating carriage of methicillin-resistant Staphylococcus aureus. Antimicrob Agents Chemother 1999;43:1412-1416.

38. Muto CA, Jernigan JA, Ostrowsky BE, et al. SHEA Guideline for preventing nosocomial transmission of multidrug-resistant strains of Staphylococcus aureus and Enterococcus. Infect Control Hosp Epidemiol 2003;24:362-386.

39. Boyce JM, Opal SM, Potter-Bynoe G, Mederios AA. Spread of methicillin-resistant Staphylococcus aureus in a hospital and after exposure to a health-care worker with chronic sinusitis. Clin Infect Dis 1993;17:496-504.

40. Kluytmans J, van Leeuwen W, Goessens W, et al. Food-initiated outbreak of methicillin-resistant Staphylococcus aureus analyzed by pheno and genotyping. I Clin Microbiol 1995;33:1121-1128.

41. Lessing MP, Jordens JZ, Bowlwer IC. When should health care workers be screened for methicillin resistant Staphylococcus aureus? J Hosp Infect 1997;35:320-321.
42. Struelens MJ, Ronveaux O, Jans B, Mertens R, Groupement pour le Dépistage, Étude et la Prévention des Infections Hospitalières. Methicillin-resistant Staphylococcus aureus epidemiology and control in Belgian hospitals, 1991 to 1995. Infect Control Hosp Epidemiol 1996;17:503-508.

43. Karchmer TB, Jernigan JA, Durbin BM, Simonton BM, Farr BM. Eradication of methicillin-resistant $S$. aureus (MRSA) colonization with different regimens [abstract 65:42]. Presented at the Ninth Annual Meeting of the Society for Healthcare Epidemiology of America; April 18-20, 1999; San Francisco, CA.

44. Kotilainen P, Routamaa M, Peltonen R, et al. Eradication of methicillin-resistant Staphylococcus aureus from a health center ward and associated nursing home. Arch Intern Med 2001;161:859-863.

45. Walker ES, Vasquez JE, Dula R, et al. Mupirocin-resistant, methicillin-resistant Staphylococcus aureus: Does mupirocin remain effective? Infect Control Hosp Epidemiol 2003;24:342-346.

46. Vasquez JE, Walker ES, Franzus BW, et al. The epidemiology of mupirocin resistance among methicillin-resistant Staphylococcus aureus at a Veterans Affairs hospital. Infect Control Hosp Epidemiol 2000;21:459-464.

47. Miller MA, Dascal A, Portnory J, Mendelson J. Development of mupirocin resistance among methicillin-resistant Staphylococcus aureus after widespread use of nasal mupirocin ointment. Infect Control Hosp Epidemiol 1996;17:811-813.

48. Coia JE, Duckworth GJ, Edwards DI, et al.; Joint Working Party of the British Society of Antimicrobial Chemotherapy, the Hospital Infection Society, and the Infection Control Nurses Association. Guidelines for the control and prevention of methicillin-resistant Staphylococcus aureus (MRSA) in healthcare facilities. J Hospital Infection 2006;63:1-44.

49. Loeb M, Main C, Walker-Dilks C, Eady A. Antimicrobial drugs for treating methicillin-resistant Staphylococcus aureus colonization. Cochrane Database Syst Rev 2003;CD003340.

50. Hoffmann KK, Kittrell IP. North Carolina guidelines for control of antibiotic-resistant organisms, specifically methicillin-resistant Staphylococcus aureus (MRSA) and vancomycin-resistant enterococci (VRE). 1997. Available at http://www.unc.edu/depts/spice/guide2. html

Address reprint requests to: Dr. Lena M. Napolitano Department of Surgery University of Michigan Health System Room 1C421, University Hospital, Box 0033 1500 E. Medical Center Drive Ann Arbor, MI 48109-0033

E-mail: lenan@umich.edu 
